\title{
What Once was Sick is now Bad: The ShifT FROM Victim to DeVIANT IDENTITY for those Diagnosed with Fetal Alcohol Spectrum Disorder ${ }^{1}$
}

\author{
ERIN DEJ
}

\begin{abstract}
Fetal alcohol spectrum disorder (FASD) is constituted by different networks and institutions. I demonstrate that while the symptoms associated with FASD do not differ from childhood to adulthood, their conceptualization and thus societal and governmental responses to individuals with FASD change dramatically. This research is theoretically grounded in Rose's work on psy-identities and Hacking's concept of a looping effect. To unpack the reconstitution of the FASD identity from childhood to adulthood I have identified two linked but distinctive loops - that of the promising child and the deviant adult. These two loops conceptualize the different institutions, stakeholders, and knowledges that take interest in the "FASD child" and those that constitute the "FASD adult" identity within the criminal justice system.
\end{abstract}

Keywords: fetal alcohol spectrum disorder; identity; looping effect; psy-discipline; critical criminology; First Nations/Métis/Inuit communities

Résumé. Les définitions liées à l'ensemble des troubles causés par l'alcoolisation foetale (ETCAF) proviennent de différents systèmes de réseaux et institutions. Je démontre que la conceptualisation des TCAF et les approches sociales et gouvernementales envers ceux qui en souffrent changenr radicalement malgré le fait que les symptômes associés aux TCAF demeurent les mêmes de l'enfance à l'âge adulte. À l'intérieur de cette recherche, je me réfère au travail de Rose sur les «identités psy» et de Hacking sur l'effet de boucle. Afin de révéler la reconstitution de l'identité associée à l'adulte qui souffre de TCAF, j'ai identifié deux boucles qui sont à la fois liées et distinctes - celle de l'enfant prometteur et celle de l'adulte délinquant. Ces deux boucles nous aident à conceptualiser les différentes institutions, les parties prenantes et les connaissances qui s'intéressent à «l'enfant souffrant des TCAF » et ceux qui servent à définir l'adulte TCAF à l'intérieur du système pénal.

Mots clés: l'ensemble des troubles causés par l'alcoolisation foetale; l'identité; l'effet de boucle

1. The author would like to thank Dr. Dawn Moore and Dr. Jennifer Kilty for their help with earlier drafts of the paper and to Dr. Steven Bittle for his helpful comments. This research was supported by the Social Science and Humanities Research Council. 
Thal alcohol spectrum disorder (FASD) is constituted by different actors, networks and institutions. Whereas in childhood, the FASD ${ }^{2}$ identity is salvageable victim, in adulthood the FASD identity is deviant, dangerous, and irredeemable. I explore the shift in the FASD identity from childhood to adulthood and the governing effects produced from these differing discourses. Conceptualizing adults as responsible for their behaviour is not unique to FASD. However, the cognitive and behavioural symptoms associated with FASD (such as impulsivity, being overtly affectionate, an inability to grasp basic concepts) cast FASD children $^{3}$ as victims and FASD adults as deviant. FASD is simultaneously regarded as a mental illness and a marker of deviance, with the two paradigms mutually reinforcing one another. The aim of this paper is to think critically about the FASD diagnosis as a psy-identity. Although psy-knowledges ${ }^{4}$ claim to be natural/objective/neutral, the meaning of the diagnosis shifts from sick in childhood to bad in adulthood thus calling for different governing responses. The racialization of FASD as an "Aboriginal problem" is indicative of the value-laden knowledges used to produce the diagnosis.

FASD is an umbrella term encompassing all possible effects of prenatal exposure to alcohol (Fast and Conry 2004:161). A diagnosis requires varying degrees of pre and/or postnatal growth retardation, facial anomalies, central nervous system dysfunction, and confirmation of maternal consumption of alcohol during pregnancy (Abel and Hannigan 1995; Michaud and Michaud 2003). Some scholars (Armstrong 2003, Golden 2005) are critical of the expanded diagnosis, focusing on FASD as a tool of gender regulation and cite its emergence and acceptance by the medical community in the early 1970 s as a method of controlling women's reproduction. Tait (2007) studies the social construction of FASD amongst Aboriginal communities and its use as a tool to homogenize Aboriginal peoples and simplify complex social problems. Socially marginalized people are reframed as deviant biopsychological subjects (Rose 2000a; Armstrong 2003; Tait 2007). Building on this critical literature, I consider FASD as a shifting identity from childhood to adulthood, based in part on the claims of different knowledge producers. It is

2. The term FASD will be used to refer to fetal alcohol syndrome, fetal alcohol effects, partial fetal alcohol syndrome, alcohol related birth defects and alcohol-related neurodevelopmental disorders.

3. I use the terms FASD child and FASD adult to be critical of the notion that an individual has this syndrome and to acknowledge that while those labelled with FASD have a variety of identity markers, a psy-identity takes over other facets of their identity to various degrees, and in relation to other markers such as race; class; and gender, to become a master status (see Cohen 1985).

4. By psy I am referring to psychology, psychiatry and other disciplines related to these areas. 
important to recognize that questioning how and why FASD is constituted as a pathology warranting criminal justice intervention has no bearing on whether or not FASD is real in the biological sense of the term. My point is that the deployment of the identity, real or not, has real effects.

This research draws on multiple methods: document analysis of government and advocacy material, criminal court cases, and Hansard debates from 1968-2008; and eight semistructured interviews with advocacy groups, government personnel, and not-for-profit organizations. Interviews were conducted either in person or by phone throughout Canada between June and December 2007 by cold-calling and some snowball sampling; participants were asked questions related to their professional capacity. While many themes emerged, the focus of this paper centres on applying Hacking's looping effect to the construction of two distinct but related psy-identities — the FASD child and adult.

\section{Psy-IDentities as UnNatural}

Psy-disciplines rely on classification tools, observation, and measurements to produce knowledges claiming to be objective and neutral (Zachar 2000). The transformation of the FASD identity from childhood to adulthood contradicts the premise that diagnoses are innate. Rather than providing a uniform and objective measurement of symptoms, the FASD diagnosis imposes particular normalization techniques. Ignoring the social context of diagnosis characteristics leaves individuals to be normalized and controlled (Rose 1988; Rosenberg 2002). Although diagnoses are debated, negotiated, and even voted upon (as is the case with each new version of the Diagnostic and Statistical Manual, Kutchins and Kirk 1997), once pathologized, psy-identities are presented as discoverable, natural phenomena. Likewise, psy-identities are not consistently applied, but take different forms and affect individuals to greater or lesser degrees depending on social circumstances.

FASD is described as an epidemic in First Nations, Métis, and Inuit communities (House of Commons Debates 2003; 2008), so an analysis of FASD must include a discussion of the identity as "an Aboriginal problem" (Michaud and Michaud 2003). The introduction of FASD in two Lancet articles in 1973 uses scientific rhetoric to mask the racialization of the diagnosis. Of the eleven case studies used to create the diagnosis, more than half (six) of the children were Aboriginal; their facial features were measured and assessed against white children to create the "FAS face" (Jones et al. 1973; Jones and Smith 1973). Although FASD was initially documented through physical measures it was quickly ac- 
cepted as a scientific diagnosis to explain cognitive and behavioural problems as well.

Just as the case studies are racialized, the link between class and FASD is built into the diagnosis. For example, the authors of the Lancet articles remark that four of the eleven patients were living in foster homes and that eight of the families were living on social assistance (Jones et al. 1973; Jones and Smith 1973). The scientific value of referencing the patients' socioeconomic status is not apparent; conversely, the reference imbeds class into the FASD diagnosis by making it synonymous with poverty.

Rose (1998:105) explores the way psy-disciplines use pathologization as a "...technique for the disciplining of human difference." Codifying individual behaviour into categories - such as disease, syndrome, and disorder - allows disciplining of difference. Rose (1988:4) suggests: "The idea of a unified, coherent, self-centered subject has been upset by the multitude of ways our selves are shaped, but psychology likes to pigeon hole into one identity." The FASD diagnosis explains any number of cognitive and behavioural actions as resulting from exposure to alcohol in utero, thus implementing truth claims about an individual and enforcing specific governing technologies. Rose's (1988; 1998) work finds that the psy-disciplines develop precise governing mechanisms to persuade the abnormal to become normal. Although both identities are governed on principles of discipline, FASD children and adults are distinct because different technologies of government act upon their conduct (Rose 2000b). Children are targeted by the public health/welfare systems and FASD adults are identified, often for the first time, within the criminal justice system. The inconsistencies between the two FASD identities demonstrate the psy-disciplines' inability to proclaim a singular truth.

\section{The Looping Effect}

Rose's concept of psy-identities explains how technologies govern people. Thinking critically about FASD, however, requires moving beyond an individualized lens to consider FASD identities on a collective scale. Here, Hacking's concepts of making up people and the looping effect demonstrate the variety of knowledges constructing an identity and how identity can be reformed. Hacking (2004:279) refers to the looping effect as: "...the ways in which those who are classified, and who are altered by being so classified, also change in ways that causes systems of classification be modified in turn." In the case of the FASD child and 
adult identities, it is the lay knowledges (for example parents of an FASD child) and professional knowledges (social welfare or criminal justice systems) that constitute two different identities based on one diagnosis.

Hacking's (1991; 1999; see Pfohl 1977) project on the reidentification of child abuse in different temporal and social contexts allows us to think about the FASD identity in transformative terms. Hacking illustrates how narratives about child abuse can change over time, effectively altering an individual's past, present, and future identities. When thinking about FASD in terms of reconstituted identities, there are two connected but ultimately distinct loops - that of the child and adult. Both identities have the same characteristics but produce either a child loop of an innocent victim who is worth saving or an adult loop of an undeserving and hopeless criminal. The temporal linkages, which in the child abuse identity produce a lifelong narrative, are missing from the FASD identity. The division between childhood victim and deviant adult is a messy one and within each discourse some knowledge is silenced. Figure 1 oversimplifies the distinction between the two loops, especially as it relates to adolescence when this shift often occurs, but is a helpful tool to explore the division between the two identities.

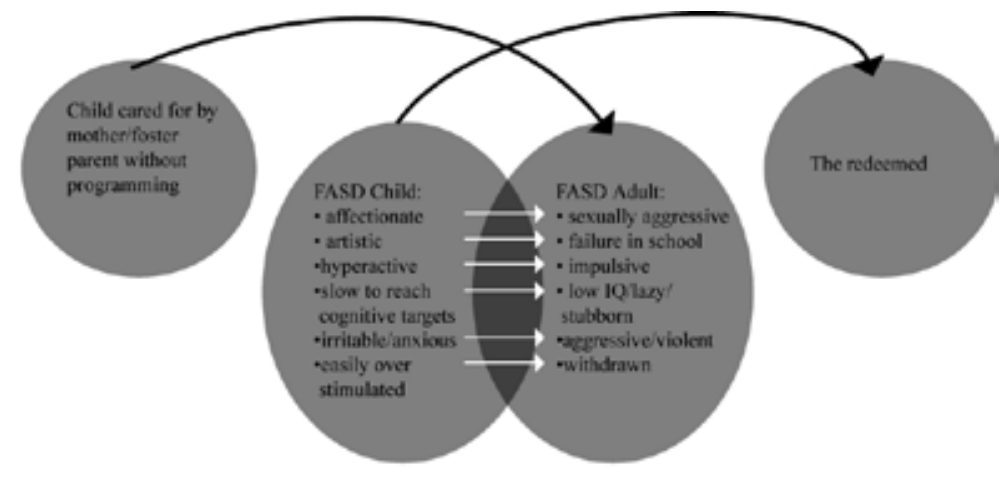

Figure 1: FASD ldentitics

The separation between the two identities is illustrated in a speech made by California Governor Pete Wilson when denying a reversal of the death sentence of someone with FASD. The governor claimed: "As great as is my compassion for Robert Harris the child, I cannot excuse or forgive the choice made by Robert Harris the man" (Golden 2005). The governor's message is that the child and the adult are two different people. This division is necessary in order to demonize the FASD adult; 
otherwise, it would appear that an innocent victim is being sentenced to death. By bridging the two loops through their common denominator — the diagnosis - the dichotomy between the victimized child and the deviant adult are blurred. Using the psy-diagnosis is precisely what distinguishes FASD from the broader criminalization of deviant adults. As Smart (1989:20) describes, the law reorients psy-knowledges to suit its purposes, such as in the case of best interests of the child. For FASD the diagnosis is manipulated by the criminal justice system as more or less medicalized to suit the needs of the system (often by making the FASD adult responsible for his or her actions).

\section{The Victimized Child}

Psy-experts identify the FASD child as an innocent victim with the potential to be a productive citizen, given professional and timely interventions. The FASD child identity is medicalized so that the scientific community, psy-disciplines, and community programmers can have virtually uninhibited access to the individual and his/her environment. Medicalization literature contains privileged discourses that do not exist in a vacuum, but are shaped and understood by larger social and political constructs (Rosenberg 2002). Critics of medicalization demonstrate how these discourses transform social, political, and historical phenomena into pathologies. For example, one research participant (a public servant; 3 August 2007) ${ }^{5}$ commented that overrepresentation of Aboriginal people in the criminal justice system occurs partly because FASD is one of the first illnesses physicians consider in an Aboriginal patient. In contrast, non-Aboriginal patients are more likely to receive a diagnosis such as attention deficit-hyperactivity disorder (ADHD).The medical community and society in general fail to

remember that FAS/FAE occurs in any society. While there are no statistics to show how many Inuit have FAS/FAE, the incidence is not necessarily any higher than that of other groups. (McGrath 1998:5)

This reality is forgotten or ignored because, as one research officer studying the Inuit experience (19 August 2007) claimed, issues such as poverty, disenfranchisement, and disconnectedness can be explained away with the FASD diagnosis (Tait 2007). By taking a purely medicalized approach to the FASD identity, the production of the FASD child as a victim is appealing; children are not meant to be sick and so there must be someone to blame for their illness.

5. The titles of the research participants and their organization are not revealed as this would compromise their anonymity. 
To sustain the victim identity, only certain parents/caregivers have the resources and opportunity to participate in knowledge production, leaving others silenced. Those children whose narratives are not acknowledged by the medical discourse are, therefore, not recognized as innocent. Children who reside with their biological mothers are rarely accounted for in the FASD literature, likely because few retain custody of a child diagnosed with FASD. Children who move from one living environment to another, most often foster homes, may not receive the attention and special care expected for a child with FASD; this is an important consideration given that more than half of FASD children live in foster care or in adopted homes (Clarren and Astley 2002). Very rarely are the experiences of parents/caregivers caring for an Aboriginal FASD child heard, with the exception of those children who have been adopted by white parents.

The medical and psy communities subjugate the knowledges of parents/caregivers who do not or cannot invoke approved governing techniques. These parents are "condemned as perpetrators" for refusing their children the possibility of a positive future (Chen 2005). Research participants (a public servant; 3 August 2007) (director of an early intervention centre; 20 June 2007) noted that women likely to be at high risk of bearing a child with FASD and FASD children often have limited access to social programs due to poverty, a lack of education, inaccessible medical care, and geographic isolation. Among these systematic barriers are health inequalities suffered by First Nations, Métis, and Inuit peoples, including discrimination amongst health care providers and the lack of accessible health care that contributes to poor health in many Aboriginal communities (Tang and Browne 2008). By eliminating marginalized children, the FASD child identity can be narrowly defined by its psycharacteristics (Rose 1998), becoming a worthwhile investment of social programs to produce productive adults.

\section{Reaching the Optimum Potential}

Psy-experts view FASD children as capable of becoming productive future citizens. The key to success ${ }^{6}$ is reaching children at a young age to allow sufficient time to "fix" them and their potential future behaviour. As one psychologist noted, although "we should never write children off, it can be difficult to change long-lasting, maladaptive patterns later in life" (Bruer 1999:6). Limiting the scope of the victim identity to children under the age of six lays the foundation for the construction of the

6. By success I am referring to those children who are able to manage their symptoms in a way that they can participate fully in society, for example, as a taxpayer (see below). 
deviant adult loop made up of those who do not receive adequate programming in the specified time.

The notion of optimum potential emerges from the rhetoric that treating children with FASD is an investment in the future. Optimal potential, as described in the neurodevelopmental discourses, is based on the idea that children who receive the best developmental experiences will be increasingly productive. It describes indicators of readiness as a way to measure the success of a young child through specific criteria, including: a lifelong readiness to learn, social awareness, efficiency, and adaptability. These indicators provide a normative milestone by which all children are assessed to determine their potential value as citizens, regardless of differential personal and social circumstances (Henderson 2005). Early years programs targeting children age 0-6 exemplify the focus of governing strategies for children. For example, Ontario's Best Start program leads with the mantra: "Healthy babies are more likely to develop into healthy children, and healthy children are more likely to grow up to be healthy teenagers and healthy adults" (Ontario 2007). Programs such as Best Start use optimum potential as a mode of classification (Rose 1998; Rosenberg 2002) whereby cognitive ability and behaviour are quantified to evaluate programs for their ability to cure symptoms with no reference to children who do not access care before the age of six, who require continued care, or who are not "successful."

\section{The Medicalization of FASD}

There are few FASD specific social support services. ${ }^{7}$ Most children who gain access to services between the ages of 0-6 have an integrated support services network. To demonstrate progress towards reaching a child's optimum potential the cognitive and behavioural problems associated with FASD are isolated rather than assessed as a single diagnosis (Wentz 2002). This "quantification of the human soul" (Rose 1998:112) results in an understanding of the FASD diagnosis as a series of independent, manageable symptoms. Because of this, many of the disabilities associated with FASD are not viewed as permanent with an assumption that children can move past the cognitive and behavioural barriers that are associated with deviancy in adulthood.

A climate of hope exists for FASD children when small, manageable issues are addressed rather than the larger context within which the symptoms form. As a public servant (3 August 2007) explained, programming is directed at problems such as self-regulatory, developmental

7. One exception is Breaking the Cycle, offered by Mothercraft with the mandate of working with biological mothers and their FASD children ages $0-6$. It is only available in Toronto, Ontario (Leslie 2007). 
or communication issues, to name a few (see also, Leslie and Roberts 2004). A significant portion of the interventions are devoted to changing a child's environment such as painting the walls a calming colour, lowering noise levels, and working out a routine (Leslie and Roberts 2004). Such targeting is limiting and ignores the social implications of having a diagnosis of FASD; ultimately, there is an assumption that the illness can either be cured or effectively managed in childhood, making adult programming unnecessary (Bruer 1999). ${ }^{8}$ By framing FASD in childhood as almost curable, the FASD adult loop assigns a label of deviant to those who have not learned to manage their cognitive and behavioural problems.

\section{Blaming Others}

Psy-experts constitute FASD children as victims and thus place blame for their deficiencies externally. In cases where children are removed from their biological parents blame is often placed on the biological mother for drinking during pregnancy and/or on society for failing to force the mother to stop drinking. The biological mother (the father is typically omitted from the discussion) is said to have inflicted trauma onto the lives of her children and it becomes the community's responsibility to save the child (Chen 2005). The lack of analysis at the sociohistorical level inflames the rhetoric of "bad mothers," particularly in the case of Aboriginal women and communities where the impacts of colonization, including residential schools, contemporary socioeconomic marginalization, and discrimination, are ignored in favour of biological imperatives imposed by so-called unfit mothers (Tait 2003).

Moreover, nonbiological parents/caregivers experience guilt trying to ensure the best interventions for their children. Parents are easily criticized for not trying hard enough or in the right ways to facilitate the success of their child/victim (Buxton 2004). For example, in an interview conducted by CBC Radio (2007), the adopted mother of Russ, a thirtyyear-old man diagnosed with FAS, tells the story of a child who was continually behind on developmental milestones. She explains that given the lack of knowledge and resources about FASD, blame for Russ' multiple incarcerations fell on her shoulders. This mother states that because she was not able to keep track of her son twenty-four hours a day, criminal justice actors told her she was a bad parent. An interview participant (mother of FASD child and advocate; 18 June 2007) maintained that the message these stories send is that unrelenting perseverance is neces-

8. Although it is clear that these programs are not benign, without systematic review of the programs, participants, and their parents, we cannot evaluate whether they are non/ coercive, paternalistic, or racist. 
sary for success. As the looping effect is mutually reinforcing (Hacking 2004), when parents accept the blame for their child's failure to reach the optimum potential, there is a greater potential for the victim discourse to be embedded in the individual's identity.

\section{After Optimum Potential}

The discourse concerning FASD children ages $0-6$ is clear: they are victims and with substantial intervention from medically informed programming there is hope that they will become successful adults. As children reach school age, this identity is blurred as the child and adult loops connect. There is less emphasis on the entitlement of older children to have access to support services and an expectation that these children will adapt to their environment, rather than the environment accommodating them. As understood through the looping effect, parents/caregivers and FASD children reinforce a more ambiguous identity for school-aged children by their acceptance of sole responsibility for finding and fighting for services, in contrast to government programs meant to save the younger children. In a reconfiguration of Hacking's (2004) looping effect this blurriness denotes a shift from one identity to another rather than a single identity. The shift is illustrated by a research participant's (director of a research network; 10 July 2007) claim that it becomes the responsibility of the parents/caregivers to educate teachers who do not know about FASD. For each new teacher the FASD student encounters, parents are required to provide information on how to best manage their FASD children. This leads many parents/caregivers to choose specialized private schools or homeschooling for their children. ${ }^{9}$

Despite the messiness with which identities take shape, are imposed, and are taken up through the looping effect, the transition between the victim and deviant identity appears seamless as the symptoms associated with FASD are recast. For example, young children with FASD are described as extremely affectionate. They have an insatiable desire for affection and seek embraces from anyone who will give them and readily accept new individuals into their lives (Dorris 1989; Buxton 2004). Many FASD narratives describe this indiscriminate appeal for affection as a positive attribute. In adulthood, however, this same trait is described as a major cause of sexual deviancy (Novick 2002).

9. Of course, these options are only open to parents/caregivers with the financial and social resources to pursue an alternative to public education, further marginalizing some families dealing with FASD. 


\section{The Deviant Adult}

The FASD adult loop is built on the same cognitive and behavioural symptoms associated with the FASD diagnosis, but the discourses around the characteristics are drastically different. No longer do community and school based programs and government agencies add to the discourse about FASD. Instead, criminal justice officials become the dominant knowledge producers, using the FASD diagnosis to depict affected adults as responsible for their decisions and behaviours, and thus potentially dangerous and hopeless. ${ }^{10}$ Although the adult identity is a marked departure from the child identity, the two loops are linked by their reliance on the same characteristics and diagnosis.

The apparently stark contrast between the FASD identities is explained in part by the demedicalization of FASD in adulthood. Golden (1999:271) defines demedicalization as: "a political and social process, reflecting the interests of particular groups in returning definitions of deviance to the legal arena, the moral realm, and the court of public opinion." Referring specifically to FASD, Golden (1999:271) emphasizes that demedicalization does not mean the diagnosis is being ignored by the medical community; however, the "explanatory power of the diagnosis is eroding as the diagnosis does little to afford special consideration to those classified as FASD." Stakeholders such as politicians, agents of the criminal justice system, and the media produce the dominant knowledges about FASD adults rather than medical experts. Golden (1999; 2005) uses the term practically to study death sentence appeals; I am using it in a theoretical sense to understand how a new loop appears for FASD adults and is connected to but distinct from the FASD child. The loop in childhood grants significant power to the medical knowledges that make up the FASD identity. In adulthood, the criminal justice system demedicalizes FASD as seen in criminal justice doctrines regarding mental illness, such as fitness to stand trial or being found not criminally responsible, which are not designed and rarely implemented with FASD in mind (Roach and Bailey 2009).

Just as the FASD story emerges from the perspective of select children — those who warrant saving — not all adults diagnosed with FASD are heard. In fact, there is a dichotomy in the FASD adult identity between what I term the redeemed and the "lost cause." The former are

10. There are no reported statistics on the number of individuals diagnosed with FASD who end up in the criminal justice system, likely because there is no clear indication of the number of diagnoses given each year in the general population (Mitten 2004). Although we must be careful not to exaggerate the numbers, it is worthwhile to discuss the governing implications of a discourse that asserts a strong connection between FASD and the criminal justice system. 
those individuals who beat the odds and lead a "successful" life because they received the necessary support and treatment from medical and community officials (see Kleinfield and Wescott 2000). FASD advocates highlight their stories and use these individuals as poster children for increased awareness about programming and support.

Buxton (2004) tells the story of a woman who accepts a six-year-old girl as a foster child, despite the fact that the social worker deems her unteachable and hopeless. Through many medical and cognitive struggles, the child grows up healthy and educated, thanks to home schooling. She is successful because her mother fought for supports from the medical and social community. The story emphasizes that it is because of this perseverance that the child is now an intelligent and sociable woman who runs a small business with her mother and speaks at conferences about her life with FASD. The story ends by noting that the young woman made contact with her biological brother, who was raised by a foster family that was not sensitive to his needs as an FASD child, and was, "frequently in trouble with the law [as] he "did not get the help and support he needed"' (Buxton 2004:106). He committed suicide at age twenty-one. This is a telling contrast between the young girl and her brother. The girl, who received support and education, is recognized as successful not only as a person with FASD but as an entrepreneur and spokesperson. The boy, who did not receive these interventions in childhood, is portrayed as the antithesis of his sister (the redeemed) - he is the embodiment of a lost cause. We do not hear about him or other lost causes until they reach the criminal justice system.

\section{Responsibility and FASD}

In childhood, the victim identity prevents personal responsibility for problems (such as poor grades in school, angry outbursts, stealing) and blame is often attributed to parents/caregivers. In contrast, the criminal justice system shifts responsibility back to FASD adults for these same problems, not surprisingly given the psy-disciplines' influence on the system (Rose 1998). There is an obvious question about where youth ${ }^{11}$ fit into the paradigm of the child and adult loops. The body of research on youth as a distinct entity in the criminal justice system is well established (Doob and Cesaroni 2004; Sprott 2003). Surprisingly though, with reference to the FASD identity, there is little indication that youth are distinguished from the adult identity. Whereas an FASD youth may receive a more lenient sentence on account of the Youth Criminal Justice Act (YCJA), in terms of the justice system's reaction to the diagnosis

11. The age range attributed to "youth" in the FASD literature is inconsistent but generally ranges between $12-18$. 
the youth is demedicalized and subsequently criminalized similarly to FASD adults. For example, Roach and Bailey (2009) refer to the impact of the YCJA on sentencing but use examples of youth and adult cases interchangeably in their analysis of FASD as a mitigating or aggravating factor. Therefore, when I refer to the FASD adult identity in the criminal justice system, FASD youth are part of this loop.

Schonfeld, Mattson, and Riley (2005) refer to unwanted behaviours as a lack of moral maturity on the part of FASD youth and adults. Page (2003:78) uses the term "moral retardation" to refer to children who grow up never having learned life lessons:

It is one of the most heartbreaking experiences for adoptive families that their children persist in behaving like street urchins in spite of the good parenting they have received.

Failing to meet expectations imposed by parents, teachers, or employers are common descriptions of the adult identity (Streissguth et al. 2002; Wemigwans 2005). Moreover, when a youth with FASD performs poorly in school the diagnosis is connected to other behaviours:

By high school these students often achieve very low marks and frequently skip school, start smoking, abuse alcohol and drugs to control their pain, and engage in crime ... and sexual promiscuity. (Wemigwans 2005:22)

The belief in a "cure" for the behavioural and cognitive problems associated with FASD in childhood is a major factor contributing to the shift from a sick to a deviant identity. Inappropriate behaviour on the part of FASD adults is a sign that either they are not cured (because they failed to take advantage of the services offered to them) or that they are simply deviant.

The governing technologies adopted by the criminal justice system rely on the notion of a responsible subject, which is inconsistent with the identification of FASD individuals as morally immature. In the case of $R$ v. E.L.J (1998:4) the judge contemplates the accused's diagnosis of FASD when assessing the appropriate sentence for the numerous petty crimes he committed, such as theft, vandalism, and failure to appear in court:

... we simply cannot throw up our hands and do nothing. Neither will we help by labelling FAS and FAE youth as victims of alcohol abuse or as mental defectives, incapable of change ... to hold such an attitude is ultimately to deny the humanity of such individuals.

The judge places the standards of a responsible, law-abiding, and socially productive adult on someone who is otherwise considered completely 
irrational. The discourses that make up the FASD adult identity presume that the person can make informed, rational, and calculated choices. Responsibility thus lies with the individual in spite of the diagnosis.

\section{The Dangerousness of FASD Adults}

The FASD community asserts that there is a significant risk that FASD adults will confront the criminal justice system. Actions taken by FASD adults appear to be self-destructive and dangerous but appealing for medical intervention is increasingly difficult with age. As an FASD individual reaches adulthood, there is an expectation that the disabilities that plague FASD children are outgrown. Most often, the physical anomalies associated with the disability diminish with time and there is an assumption that cognitive and behavioural disabilities disappear as well (Streissguth et al. 1988). The criminal justice system adopts and substantiates demedicalized knowledges by their involvement with FASD persons.

Of particular concern is the lack of clear statistics on the prevalence of FASD in the criminal justice system and/or prison (Boland et al. 1998). In 2003, Chartrand and Forbes-Chilibeck counted only 40 prisoners with an FASD diagnosis. Mitten (2004) and Fast and Conry (2004) suggest that $23 \%$ of the prison population has FASD. In 2008, Roach and Bailey (2009) found 265 criminal cases mentioning FASD, including diagnosed individuals acting as a witness, victim, or accused. The lack of FASD diagnoses in Canadian prisons is attributed to the difficulty in confirming maternal consumption of alcohol. An interviewee (research officer from Correctional Service Canada; 3 December 2007) noted that the correctional assessment program is looking for an easier way to access the history of prenatal substance use, such as using risk factors to make an educated guess about the mother's drinking habits. If this occurs, "risky" behaviour will be used to claim a psy-diagnosis while subsequently making value judgements about motherhood, parenting, the individuals being diagnosed, and the social environment from which they come. Using the looping effect as our guide, the intent of this section is to demonstrate the shifting discourse that strips FASD of its victim identity and reinvents it as criminal.

The depiction of FASD youth and adults as responsible yet unable to manage themselves appropriately is linked to an increased risk of living on the streets, using alcohol and illicit drugs, and having unprotected and promiscuous sex (Streissguth et al. 2002; Clark et al. 2004; Let's Talk FASD 2007). Almost every discussion of youth and adults with FASD reports a high rate of risky behaviours, although there is no comparison to non-FASD youth (Boland et al. 1998; Page 2003; Verbrugge, 2003). 
Reducing the FASD adult identity to these sorts of activities allows the criminal justice system to intervene and impose discipline strategies. Criminal justice actors do not perceive or govern middle-class, white teens who experiment with drugs or spend a night away from home the same way as FASD youth.

The negative depictions of FASD youth and adults as potentially dangerous legitimize stricter control strategies. These strategies are distinct from their child counterpart as they rely more heavily (and sometimes exclusively) on retribution. A radio broadcast from Minnesota conveys the danger FASD youth can be to themselves and others. In profiling a residential care centre for adults with FASD, the broadcast relates the troubles caused by FASD youth to their diagnosis. The manager of the centre recalls the youths' screaming, swearing, and property destruction and associates these behaviours with their FASD. He goes on to describe the youth as "hyper-sexual" and remarks that they would likely be in prison if not for the centre (Robertson 2007). Resident Billy Nelson connects his FASD diagnosis to his dangerous behaviour, and attributes his reduction in drug and alcohol use, and being "prone to violence" to the residential centre. Nelson says: "I need to take the punches and say, hey, just get my stuff together so I can move on in life and better myself. Because if you don't better yourself, you're not going anywhere" (Robertson 2007). As Nelson connects intensive supervision and intervention with participating in fewer dangerous behaviours and becoming a better (normalized) person, he exemplifies how the FASD adult loop is mutually reinforcing. Ultimately, Nelson believes that if left to his own devices, FASD would inevitably lead to deviancy or criminality.

There is little difference between the FASD associated behaviours exhibited by children and adults, but criminal justice literature depicts the adult identity as dangerous despite the generally low severity of offences committed by FASD adults. ${ }^{12}$ For example, in R. v. R.B.M. (age 22) and $R$. v. R.F. (age 13) the charges include failure to appear in court, mischief, breaking curfew, and consuming alcohol. The most serious charges in these cases are auto theft, carrying a concealed weapon, and resisting arrest. These are hardly the crimes of "dangerous" offenders. The judges in these cases sympathize with the negative impact of FASD on the lives of the accused, but use the diagnosis to justify handing down tougher sentences, including jail time. In R. v. R.F. (2002:para. 82) the judge finds:

... that R.F.'s moral reasoning is not sufficiently developed so that she applies society's standards, rather she applies her own standards; she is very ego-centric in this regard.... She may develop sufficient sophistication of

12. More serious crimes that are associated with FASD adults are crimes of a sexual nature. Crimes range from small infractions to charges of sexual assault. See Novick (2002). 
moral judgement when she is older, say 16 or 17 years of age, so that she would participate in the social contract which is simply to do the right thing because it's good for society.

Similar to the assessment of moral retardation suggested by Page (2003), in this case the FASD diagnosis conveys the message that the accused is mentally ill and it is that impairment that leads to criminality. In R. v. R.B.M. (1990:5) the judge makes claims about the accused with FASD:

At some stage in his life he must be educated or trained to become selfsufficient, and he must be made to understand that at some early date, if he continues his present path, even a tolerant and caring society or community will give up on him so that longer and longer terms of imprisonment may become the only possible future for him.

The judge clearly states that in order for the accused to remove himself from the criminal justice system he must change the very behaviours attributed to FASD.

There is an alarming overrepresentation of Aboriginal peoples in Canada's criminal justice system (Andersen 1999). In 1999, Member of Parliament John Duncan made the connection between this statistic and the high incidence of FASD diagnosis amongst this population:

We also know that victims of fetal alcohol syndrome have traditionally and statistically provable high rates of incarceration. If we look at those two statistics independently in the broad population there is a definite linkage. If we look at them specifically in the aboriginal population, it would be very interesting to know what the link is. We are possibly understating the true impact of fetal alcohol syndrome and how it is ravaging the population, particularly in terms of the rate of incarceration of aboriginal peoples (House of Commons Debates 1999:1135).

Making the connection between the disproportionate rate of FASD diagnoses and incarceration in Aboriginal communities is not without problems. While contextualizing the discourses concerning First Nations, Métis, and Inuit peoples and FASD, it prejudicially relates alcohol use with being Aboriginal, and reiterates that those with FASD are inherently criminal and thus unredeemable. Psy-diagnoses reduce complex issues to individual problems rather than seeing them as part of the social and structural inequalities facing Aboriginal communities (Tait 2003). It also limits some individuals' ability to negotiate their identity as a more multifarious entity rather than the seemingly homogenous psy-identity. The connection between the rates of FASD diagnoses and incarceration 
in Aboriginal communities highlights the subjectivity with which the FASD identity is applied. A common theme found in the interviews for this study is the marginalization attributed to the cultural isolation of Aboriginal communities, and how this fosters a negative perception of the adult identity.

\section{The Hopelessness of FASD Adults}

If FASD adults become involved in the criminal justice system, criminal justice actors minimize the diagnosis and/or use it to invoke tougher penalties. As Roach and Bailey (2009) point out, the FASD diagnosis is sometimes reduced to a risky/dangerous characteristic (see Castel 1991) requiring a custodial sentence for the safety of the public. Alternatively, when the diagnosis is acknowledged sympathetically, often the only available programming is offered in prison. Thus, the hopelessness of FASD prisoners comes from the assertion that they do not fit in a system that is otherwise considered effective in reducing harm (Andrews and Bonta 2003; see alternatively Hagen 1997). As the deterrent effect of prison is thought to be lost on people with FASD, those who work in corrections find themselves confronted with the same individuals over and over again (Roach and Bailey 2009; Williams 2006). An interviewee (research officer from Correctional Service Canada; 3 December 2007) noted the current penal structure is unable to cope with persons with FASD, and fails to teach them appropriate decision making to avoid recidivism. Advocates are quick to point out, however, that there is no adult programming for persons with FASD, despite the relatively large number of incarcerated people with FASD. The recent case of sex offender Wayne Mumford, who is diagnosed with FASD, found that

... Correctional Service Canada offers no programs geared to inmates with FASD, or any other mental disorders that reduces an adult's learning skills to those of a young child. Rather, CSC's programs are taught at a Grade 9 level. (Appleby 2007)

At the same time, calls for programming appear to contradict the idea that FASD adults cannot be effectively treated and/or "cured." For example, Judge Barnett (2002:145) claims that the programming offered to prisoners with FASD is rarely effective, stating, "... in this work, the real success stories are hard to come by." The criminal justice system has so far adopted the point of view that without being able to pinpoint what FASD is, no intervention will work.

In the community, the resources and supports offered to children are rarely offered to adults. One article claims that when FASD youth 
turn eighteen, they "fall off a cliff" in terms of services ("Groups call for more services for adults with FASD” 2007). A number of programs would like to help adults and find resources for them, but as one research participant (police officer; 10 August 2007) described, there is a greater push to provide support for children and families coping with the syndrome. Embedded in these programs is the unspoken notion that it is too late to help adults. Similarly, a public servant (3 August 2007) stated that allocating funding appears more compassionate and resourceful when it supports prevention programs and resources for young children, rather than managing those who have already failed. She mentioned that when sponsoring programming for children "you get more bang for your buck." A Manitoba study reports that $75 \%$ of adults with FASD have absolutely no access to support services. ${ }^{13}$ They do not qualify for financial support and there are often no services available for them. In fact, in an assessment of the thirteen national services for individuals with FASD listed in the Directory of Fetal Alcohol Spectrum Disorder Information and Support Services in Canada (2005) none address adults specifically while four target children exclusively. This leads to the very predicament being assessed in this paper: "The majority of FASD-affected adults don't qualify for any support whatsoever ... so the only program that can take them, if you can call it that, is the criminal justice system" (Skerritt 2007). In their analysis of sentencing FASD adults, Roach and Bailey (2009) find that some judges recognize the disadvantages of a jail term but retain a custodial sentence because prison holds more programming options than the community. Correctional and psy-discourses characterize adults with FASD as impulsive, socially inept, and unable to appreciate the consequences of their actions. In the end, criminal justice representatives use FASD adults' failure to self-regulate as a justification to redefine them as deviant.

\section{Conclusion}

The discourses that produce the FASD child and adult identities appear to be in opposition with one another but emerge from the same characteristics that define the FASD diagnosis. Impulsivity, difficulty interacting with others, and cognitive problems are among the variety of symptoms applicable to FASD. On the surface the FASD diagnosis, like other psy-

13. There are a few important exceptions, including the FASD Life's Journey; Whitecrow Village Interdependent Living Project; the West Coast Genesis Society and the John Howard Society of Central and South Okanagan's "Gateway Mentoring Program" to help individuals with FASD who are in conflict with the law. 
identities, appears to be an objective and impartial medical category that will treat, change, and cure the individual of FASD.

Using Rose's concept of psy-identities and a reformulation of Hacking's looping effect, I examined how the child and adult FASD identities are blurred because they are based on the same characteristics despite differences in governing effects. In childhood, government and community programs use a medicalized discourse to portray children as innocent victims worthy of intervention so that they may reach their optimum potential. There is a strong belief that if FASD children receive intensive and appropriate support, their illness is almost curable. Moreover, much of the psy-literature lays blame for the cognitive and behavioural problems associated with FASD on the biological mother and parents/ caregivers, strengthening the victim component of the FASD identity.

During adolescence, the victim identity is recast as FASD adults are expected to be increasingly responsible for managing their own illness. The FASD identity is demedicalized as criminal justice system actors emerge as the new experts on FASD. The literature suggests that if supports to manage FASD were utilized in childhood, any remaining cognitive or behavioural problems are due to laziness and inherent deviancy. Subsequently, criminal justice discourses transform FASD into an excuse rather than an explanation for undesirable actions.

The First Nations, Métis, and Inuit communities are stigmatized as having a high rate of FASD, but borrowing from critical work on the subject (Hookimaw-Witt 1998; Tait 2007) I question whether this stigma comes from increased surveillance and assumptions made about prenatal alcohol exposure and deviancy in a population that is overrepresented in the criminal justice system. The FASD identity marginalizes those living in poverty and targets Aboriginal communities in a way that often transforms socioeconomic problems into deterministic scientific rhetoric.

This article serves as a starting point for examining FASD as a psydiagnosis and a social construction and begs us to reconsider how mental illness is used as a tool of governance in the criminal justice system (following from the work of Arrigo 1996; Rose 2000). Future research in this area would benefit from an investigation of the perspective of children and adults diagnosed with FASD to assess what impact (if any) the two loops have had on their identity construction. The psy-identity that materializes alongside a diagnosis of fetal alcohol spectrum disorder is built upon ideas of abnormality and hopelessness; however, critically examining the knowledges used to produce the diagnosis can help us redefine what it means to be labelled with a mental illness. 


\section{REFERENCES}

Abel, Ernest L. and John H. Hannigan. 1995. Maternal risk factors in fetal alcohol syndrome: Provocative and permissive influences. Neurotoxicology and Teratology 17(4):445-462.

Andersen, Chris. 1999. Governing aboriginal justice in Canada: Constructing responsible individuals and communities through 'tradition.' Crime, Law and Social Change 31:303-326.

Andrews, D.A. and James Bonta. 2003. The Psychology of Criminal Conduct. Third Edition. Cincinnati, OH: Anderson Publishing.

Appleby, Timothy. 2007. Disability spares man dangerous tag: Ontario. Globe and Mail, 12 November. Available at http://www.theglobeandmail.com/ servlet/story/LAC20071112.OFFENDER12/TPStory/TPNational/Ontario/ (access date: November 14, 2007).

Armstrong, Elizabeth M. 2003. Conceiving Risk Bearing Responsibility: Fetal Alcohol Syndrome and the Diagnosis of Moral Disorder. Baltimore, MD: The John Hopkins University Press.

Arrigo, Bruce. 1996. The Contours of Psychiatric Justice: A Postmodern Critique of Mental Illness, Criminal Insanity. New York: Routledge.

Barnett, C. Cunliffe. 2002. A judicial perspective on FAS: Memories of the making of Nanook of the North. Pp. 134-145 in A. Streissguth and J. Kanter, eds., The Challenges of Fetal Alcohol Syndrome: Overcoming Secondary Disabilities. Seattle: University of Washington Press.

Boland, Fred J., Rebecca Burrill, Michaelle Duwyn, and Jennifer Karp. 1998. Fetal Alcohol Syndrome: Implications for Correctional Service (Correctional Service Canada). Available at http://www.csc-scc.gc.ca/text/rsrch/ reports/r71/er71.pdf, (access date: June 11, 2011).

Bruer, John T. 1999. The Myth of the First Three Years: A New Understanding of Early Brain Development and Lifelong Learning. New York: The Free Press.

Buxton, Bonnie. 2004. Damaged Angels: A Mother Discovers the Terrible Cost of Alcohol in Pregnancy. Toronto: Alfred A. Knopf Canada.

CBC Radio Ottawa. 2007. Sounds Like Canada (access date: October 2007).

Canadian Centre for Substance Abuse. 2005. Directory of Fetal Alcohol Spectrum Disorder (FASD) Information and Support Services in Canada. Ottawa: CCSA.

Castel, Robert. 1991. From dangerousness to risk. Pp, 281-298 in G. Burchell, C. Gordon and P. Miller, eds., The Foucault Effect: Studies in Governmentality. Chicago: University of Chicago Press.

Chartrand, Larry and Ella Forbes-Chilibeck. 2003. The sentencing of offenders with Fetal Alcohol Syndrome. Health Law Journal 11:35-70. 
Chen, Xiaobei. 2005. Tending the Gardens of Citizenship: Child Saving in Toronto 1880s-1920s. Toronto: University of Toronto Press.

Clark, Erica, Jan Lutke, Patricia Minnes, and Hélène Ouellette-Kuntz. 2004. Secondary disabilities among adults with fetal alcohol spectrum disorder in British Columbia. Journal of Fetal Alcohol Syndrome International 2(e13):1-12.

Clarren, Sterling and Susan Astley. 2002. The FAS diagnostic and prevention network. Pp. 40-51 in A. Streissguth and J. Kanter, eds., The Challenge of Fetal Alcohol Syndrome: Overcoming Secondary Disabilities. Seattle: University of Washington Press.

Cohen, Stanley. 1985. Visions of Social Control. New York: Polity Press.

Doob, Anthony and Carla Cesaroni. 2004. Responding to Youth Crime in Canada. Toronto: University of Toronto Press.

Dorris, Michael. 1989. The Broken Cord. New York: Harper \& Row.

Fast, Diane K. and Julianne Conry. 2004. The challenge of fetal alcohol syndrome in the criminal legal system. Addiction Biology 9(2):161-166.

Golden, Janet. 1999. 'An argument that goes back to the womb': The demedicalization of fetal alcohol syndrome, 1973-1992. Journal of Social History 33(2):269-298.

2005. Message in a Bottle: The Making of Fetal Alcohol Syndrome. Cambridge, MA: Harvard University Press.

Hacking, Ian. 1991. The making and molding of child abuse. Critical Inquiry 17(2):253-288.

1999. The Social Construction of What? Cambridge, MA: Harvard University Press.

2004. Between Michel Foucault and Erving Goffman: Between discourse in the abstract and face-to-face interaction. Economy and Society 33(3):277-302.

Hagen, Margaret A. 1997. Whores of the Court: The Fraud of Psychiatric Testimony and the Rape of American Justice. New York: Regan Books.

Henderson, Jennifer. 2005. The years before five: Discourse and pedagogy of neoliberal childhood. Cultural Studies in Education panel: Canadian Association Cultural Studies Conference at the University of Alberta, 21 October [unpublished].

Hookimaw-Witt, Jacqueline. 1998. Any changes since residential school? Canadian Journal of Native Education 22(2):159-170.

House of Commons Debates. $36^{\text {th }}$ Parliament, $1^{\text {st }}$ Session, (16 March 1999) at 1135 (John Duncan). $37^{\text {th }}$ Parliament, $2^{\text {nd }}$ Session, (25 February 2003) at 1305 (Paul Szabo). $39^{\text {th }}$ Parliament, $2^{\text {nd }}$ Session, (13 May 2008) at 1635 (Keith Martin).

Jones, Kenneth L. and David W. Smith. 1973. Recognition of the fetal alcohol syndrome in early infancy. The Lancet 2:999-1001. 
Jones, Kenneth L., David W. Smith, Christy Ulleland, and Ann Pytkowicz Streissguth. 1973. Pattern of malformation in offspring of chronic alcoholic mothers. The Lancet 1:1267-1271.

Kleinfield, J.B. Morse and S. Wescott. 2000. Fantastic Antoine Grows Up: Adolescents and Adults with Fetal Alcohol Syndrome. Fairbanks: University of Alaska Press.

Kutchins, Herb and Stuart A. Kirk. 1997. Making us Crazy-DSM: The Psychiatric Bible and the Creation of Mental Disorders. New York: The Free Press.

Leslie, Margaret and Gary Roberts. 2004. Nurturing Change: Working Effectively With High-Risk Women and Affected Children to Prevent and Reduce Harms Associated with FASD. Toronto/Ottawa: Mothercraft and Canadian Centre on Substance Abuse.

Leslie, Margaret. 2007. BTC Compendium: Volume I - The Roots of Relationship. Ottawa: Health Canada.

McGrath, Janet. 1998. Ikajuqtigiinniq: A Resource for Fetal Alcohol Syndrome Prevention and Intervention Work. Ottawa: Pauktuutit Inuit Women's Association.

Michaud, Margaret A. and Sacha K. Michaud. 2003. Beautiful Smiles, Gentle Spirit - Fetal Alcohol Spectrum Disorder: A Misunderstood Problem. Calgary: Detselig Enterprises.

Mitten, Rae. 2004. Fetal Alcohol Spectrum Disorders (FASD) and the Justice System. In Commission on First Nations and Métis Peoples and Justice Reform. Final report, 9:1-9:38. Saskatoon: Commission on First Nations and Métis Peoples and Justice Reform.

n.a. 2007. Groups call for more services for adults with FASD. CBC News Manitoba, 14 September. Available at http://www.cbc.ca/canada/manitoba/ story/2007/09/14/fasd-adults.html, (access date: December 31 2007).

n.a. 2007. Let's Talk FASD: Parent Driven Strategies in Caring for Children with FASD. Ottawa: VON Canada.

Novick, Natalie. 2002. FAS: Preventing and treating sexual deviancy. Pp. 162 170 in A. Streissguth and J. Kanter, eds., The Challenge of Fetal Alcohol Syndrome: Overcoming Secondary Disabilities. Seattle: University of Washington Press.

Ontario. Ministry of Children and Youth Services. 2007. Programs and Services, Best Start. Available at http://www.children.gov.on.ca/mcys/english/programs/beststart/health/index. asp (access date: October 11, 2007).

Page, Kathryn. 2003. The invisible havoc of prenatal alcohol damage. Journal of the Center for Families, Children and the Courts 4:67-90.

Pfohl, Stephen. 1977. The ‘discovery’ of child abuse. Social Problems 24(3):310 323.

R v. E.L.J. [1998] Y.J. No. 19 (QL). 
R. v. R.B.M. (1990) 54 C.C.C. (3d) 132.

R. v. R.F. [2002] S.J. No. 742 (QL).

Roach, Kent and Andrea Bailey. 2009. The relevance of fetal alcohol spectrum disorder and the criminal law from investigation to sentencing. University of British Columbia Law Review 42:1-68.

Robertson, Tom. 2007. Adults with fetal alcohol syndrome face huge challenges. Minnesota Public Radio (21 November).

Rose, Nikolas. 1988. Calculable minds and manageable individuals. History of the Human Sciences 1(2):179-200. 1998. Inventing Our Selves: Psychology, Power and Personhood. Cambridge: Cambridge University Press. 2000a. Government and control. British Journal of Criminology 40:321339.

2000b. The biology of culpability: Pathological identity and crime control in a biological culture. Theoretical Criminology 4 (1):5-34.

Rosenberg, Charles E. 2002. The tyranny of diagnosis: Specific entities and individual experience. The Milbank Quarterly 80(2):237-260.

Schonfeld, Amy M., Sarah N. Mattson, and Edward P. Riley. 2005. Moral maturity and delinquency after prenatal alcohol exposure. Journal of Studies on Alcohol 66(4):545-554.

Smart, Carol. 1989. Feminism and the Power of Law. London: Routledge.

Skerritt, Jen. 2007. Disability rates worry First Nation groups. Winnipeg Free Press, 20 August 2007, p. B4.

Sprott, Jane B. 2003. Do youthful offenders reject adult punishment norms? Canadian Journal of Criminology and Criminal Justice 45(2):244-258.

Streissguth, Ann, Helen Barr, Julia Kogan, and Fred Bookstein. 2002. Primary and secondary disabilities in fetal alcohol syndrome. Pp. 25-39 in A. Streissguth and J. Kanter, eds., The Challenge of Fetal Alcohol Syndrome: Overcoming Secondary Disabilities. Seattle: University of Washington Press.

Streissguth, Ann, Robin LaDue, and Sandra Randels. 1988. A Manual on Adolescents and Adults with Fetal Alcohol Syndrome with Special Reference to American Indians. Seattle: US Department of Health and Human Services.

Tait, Caroline L. 2003. Fetal Alcohol Syndrome among Aboriginal Peoples in Canada: A Review and Analysis of the Intergenerational Links to Residential Schools. Ottawa: Aboriginal Healing Foundation. 2007. Disruptions in nature, disruptions in society: Indigenous peoples of Canada and the 'making' of fetal alcohol syndrome. Pp. 196-218 in L. Kirmayer and G. Valaskakis, eds., The Mental Health of Canadian Aboriginal Peoples: Transformations of Identity and Community. Vancouver: University of British Columbia Press. 
Tang, Sannie. Y. and Annette J. Browne. 2008. 'Race' matters: Racialization and egalitarian discourses involving Aboriginal people in the Canadian health care context. Ethnicity \& Health 13(2):109-127.

Verbrugge, Paul. 2003. Fetal Alcohol Spectrum Disorder and the Youth Criminal Justice System: A Discussion Paper. Ottawa: Department of Justice.

Wemigwans, Jennifer. 2005. FASD Tool Kit for Aboriginal Communities. Toronto: Ontario Federation of Indian Friendship Centres.

Wentz, Thomas. 2002. A national survey of state directors of special education concerning students with FAS. Pp. 89-95 in A. Streissguth and J. Kanter, eds., The Challenge of Fetal Alcohol Syndrome: Overcoming Secondary Disabilities. Seattle: University of Washington Press.

Williams, Sharon J. 2006. Is there justice in the juvenile justice system? Examining the role of fetal alcohol spectrum disorders. Justice Policy Journal 3(1). Available at http://www.cjcj.org/pdf/is there.pdf (access date March 27, 2008).

Zachar, Peter. 2000. Psychiatric disorders are not natural kinds. Philosophy, Psychiatry, \& Psychology 7(3):167-182.

Erin Dej is a PhD Candidate in the Department of Criminology at the University of Ottawa. Her current research looks at how homeless men and women who are identified as mentally ill negotiate their identity within their social sphere.

erin.dej@uottawa.ca 